D. PENDIN*, R, NORANTE, A. DE NADAI, G, GHERARDI, N.VAJENTE, E. BASSO

N. KALUDERCIC, C. MAMMUCARI, C. PARADISI, T. POZZAN, A. MATTAREI* (UNIVERSITY OF PADUA, NATIONAL RESEARCH COUNCIL, AND VENETIAN INSTITUTE OF MOLECULAR MEDICINE, PADUA, ITALY)

A Synthetic Fluorescent Mitochondria-Targeted Sensor for Ratiometric Imaging of Calcium in Live Cells

Angew. Chem. Int. Ed. 2019, 58, 9917-9922.

\section{A Mitochondria-Targeting Calcium Dye}

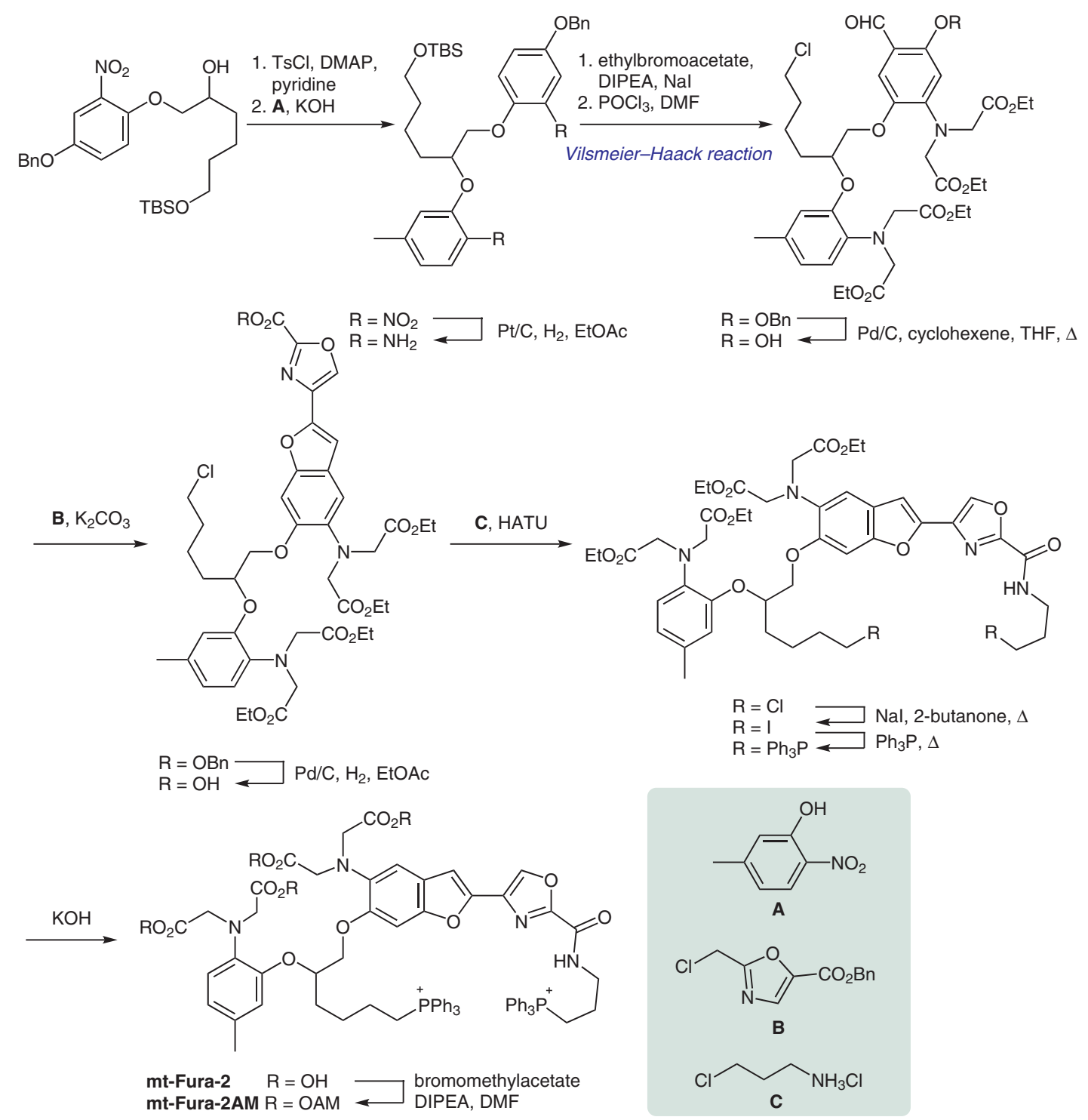

\section{Category}

Chemistry in

Medicine and

Biology

\section{Key words}

calcium Imaging

fluorescent dye

Fura-2

mitochondria

targeting

live cell imaging
Significance: $\mathrm{Ca}^{2+}$ signaling is central to several essential physiological processes. Synthetic dyes offer a convenient means to measure $\mathrm{Ca}^{2+}$ concentration in live cells. The authors describe the synthesis of mt-Fura-2(AM) as the first ratiometric $\mathrm{Ca}^{2+}$ dye that targets mitochondria. This probe overcomes the limitations of other sensors such as poor mitochondrial localization, leakage, cytotoxicity, and low photobleaching resistance.

SYNFACTS Contributors: Dirk Trauner, Bryan S. Matsuura Synfacts 2019, 15(08), 0935 Published online: 18.07.2019 DOI: 10.1055/s-0039-1689853; Reg-No.: T06319SF
Comment: Mt-Fura-2 was synthesized in 17 steps from commercially available starting materials. Derivatives of mt-Fura- 2 containing one, two, or three phosphonium cations were synthesized and it was found that two phosphonium cations were optimal for mitochondria targeting. The authors demonstrated the superiority of mt-Fura-2AM over rhod2-AM, a non-ratiometric calcium dye, and found that it was suitable for use in cells in which genetically encoded $\mathrm{Ca}^{2+}$ indicators are difficult to transfect. 